\title{
Exploring the Use of Stakeholder Analysis Methodology in the Establishment of a Living Lab
} Marius Imset, Per Haavardtun, and Marius Stian Tannum

\author{
"Interdependent people combine their own efforts with" \\ the efforts of others to achieve their greatest success. \\ Stephen Covey (1932-2012) \\ Professor and author of \\ The 7 Habits of Highly Effective People (1989)
}

\begin{abstract}
This article explores how to conduct a cost-effective stakeholder analysis to investigate opportunities and interest in establishing a living lab for an autonomous ferry connection. Using an action research approach, we share our experiences with the process and results, and we reflect openly on the strengths and weaknesses of both the stakeholder methodology generally as well as our own implementation specifically. According to the cyclic nature of action research and experiential learning, the research was conducted in two iterations, with the second iteration drawing upon input from the first. We compare and discuss these two approaches in terms of costs and benefits from a practitioner's perspective. The article provides a contribution to stakeholder analysis methodology for complex, multi-stakeholder innovation initiatives, such as living labs.
\end{abstract}

\section{Introduction}

Unmanned vessels are now fast turning from vision to reality (Øvergård et al., 2017), and the first autonomous commercial cargo ship, the Yara Birkeland, is scheduled for service in Norway in 2020 (Skredderberget, 2018). Informed about these developments, the public authorities in the Norwegian municipality of Tønsberg organized, in 2016, a dialogue meeting including industry and other stakeholders, aimed at replacing the existing 12-person ferry called the "Ole 3" (Figure 1), with a new environmentally friendly and autonomous ferry, named the "Ole 4". The idea and process were well received but did not result in any follow-up projects from Tønsberg municipality.

However, the process sparked further interest among a group of faculty members from the maritime and engineering departments at the University of South-Eastern Norway, who are the authors of this article. We obtained, in 2017, funding for a small follow-up project with a focus on navigational risk analysis related to automation. The comfort and safety of the passengers, as well as other nearby vessels and people, is paramount both in regular service and in case of incidents and emergencies. As part of the risk analysis, some interviews were conducted with the end users, including the ferry operator and passengers. However, in order to pursue the development of an autonomous ferry, including systematic involvement of end users, relevant organizations, and industry, a larger project based on more formalized collaboration would be needed. In order to prepare the ground for such an initiative, we decided to use an open innovation approach (Chesbrough, 2006; Tanev, 2011) and started to search for a specific methodology.

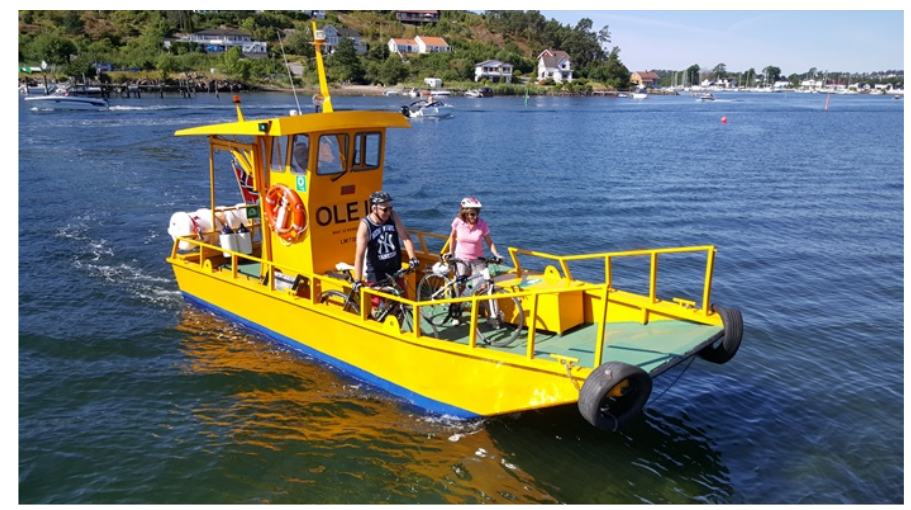

Figure 1. The "Ole 3" 12-person ferry (Photo by Tønsberg Sjømannsforening, used with permission) 


\section{Exploring the Use of Stakeholder Analysis Methodology in the Establishment of a Living Lab Marius Imset, Per Haavardtun, and Marius Stian Tannum}

The quadruple-helix model (Arnkil et al., 2010; Miron \& Gherasim, 2010) describes how industry, universities, users, and public organizations can work together to create a fruitful environment for innovation. According to De Oliveira Monteiro and Carayannis (2017), the linkages between these four sectors are indispensable for boosting innovation and productivity growth. The living lab methodology (Keyson et al., 2017; Ståhlbröst, 2008) implements a quadruple-helix model into an operational arena for innovation and provides a set of concepts, guidelines, and tools to help practitioners establish and organize these links into co-creation processes.

We chose to apply to the living lab methodology presented by Robles, Hirvikoski, Schuurman, and Stokes (2017) as the basis for an initiative with the goal of establishing a living lab around the Ole 3 ferry, and potentially other ferries as well. Living labs are concerned with generating value and benefits, in particular for end users, but also for the wider set of stakeholders. According to Logghe and Schuurman (2017), involving stakeholders is likely to encourage positive perceptions of the process and improve the quality of output and results. Stakeholders are "any group or individual who can affect or is affected by the achievement of the organization's objectives" (Freeman, 1984), so the task of identifying, understanding, and involving all relevant stakeholders in complex quadruple-helix environments may be quite costly, while the benefits, in particular in early phases, is uncertain. The use of panels has been presented as one useful method to handle stakeholders (see, for example, Schuurman \& De Marez, 2012), but the applications seem to be restricted to processes focusing on end users. Although end users represent a central stakeholder group in a living lab, we found support in the literature that other parts of the quadruple helix may be more important, in the earliest stages, to the chances of success (Jonker \& Foster, 2002; Savage, 1991). Also for living lab development, Schuurman (2015) emphasizes the importance of approaching the establishment of a living lab from the "macro" perspective, with a particular focus on the organizational level.

\section{Research Problem}

A broad stakeholder analysis appears to be a central and critical activity in the early stages of both innovation projects in general and in the establishment of a living lab in particular before a formal project and funding are in place. However, we found that there is a lack of practice-oriented research and more detailed guidelines on how to conduct such an analysis in living lab contexts. One practical aspect of obvious importance is the need to balance costs and benefits (Drèze \& Stern, 1987). Thus, we address the following research question:

How can a cost-effective yet valid and reliable stakeholder analysis be conducted as part of an early-stage initiative in the establishment of a living lab?

\section{Methodology}

Being both researchers and practitioners engaged in the Ole 3 ferry project, we have chosen to address the research problem by the use of an action research methodology. Action research is also recommended as an interesting and suitable approach to living lab research (Logghe et al., 2017; Ståhlbröst, 2008).

According to Greenwood and Levin (2006), action research is social research carried out by a team that encompasses researchers and members of an organization, community, or network that seek to improve the participants' situation. Action research consists of a set of main tasks, which we describe below in the context of how we have addressed them in our research:

1. Define the problem to be examined: We (the research group/participants) met and discussed our goals and challenges, which resulted in the research problem and question described above.

2. Cogenerate relevant knowledge about the problem: We conducted a literature review on living labs and stakeholder analysis methodology, attended conferences, discussed the topic with other scholars and colleagues, and drew on extensive personal experience from various regional development projects. Based on this, we developed a framework for the stakeholder analysis and defined a process on how to conduct it.

3. Take actions to solve the problem: We conducted the stakeholder analysis and had frequent communication during the process.

4. Collect and interpret results: We obtained results, which we summarized in tables and analyzed. 


\section{Exploring the Use of Stakeholder Analysis Methodology in the Establishment of a Living Lab Marius Imset, Per Haavardtun, and Marius Stian Tannum}

\section{Reflect on the process and iterate the action research} cycle for increased learning: We discussed and documented our findings, experiences, and lessons learned. As both action research and other models for experiential learning (Kolb, 2014) emphasize the cyclic nature of knowledge development, we undertook two iterations, where the first provided input for the latter.

\section{Research design}

The research design is the blueprint that enables the researcher to come up with solutions to the research problem, guiding the various stages of the research (Frankfort-Nachmias \& Nachmias, 2008). In our research, it implies the practical execution of the stakeholder analysis. As our basis, we have chosen the process described by Reed and co-authors (2009), which consists of the following steps: 1) Identify stakeholders, 2) Classify stakeholders, 3) Investigate the relationships between stakeholders, and 4) Reflect on the results and process.

According to the principles of action research and the nature of experiential learning, we adjusted the research design from the first to the second iteration to account for lessons learned. Thus, in the following sections, we describe each iteration, including similarities and differences in research design, as well as results and reflections according to an action research methodology.

\section{The First Iteration}

In this section, we summarize the first iteration of our action research study while emphasizing relevant methodological issues and reflections. For further details of this first iteration, please see our earlier paper on this topic (Imset et al., 2018).

\section{Step 1: Identification of stakeholders}

We used the framework provided by Ståhlbröst and Holst (2012) as a starting point for describing four main stakeholder groups for living labs: companies, researchers, public organizations, and end users. We decided to limit our scope to the Ole 3 project, making this a mesolevel approach to living lab development (Schuurman, 2015). As a tool in our discussion, we found the 17 stakeholder roles identified by Nyström, Leminen, Westerlund, and Kortelainen (2014) to be helpful. Examples of such roles are advocate, producer, coordinator, and messenger. Together, we generated a list of 25 stakeholders that seemed relevant for the Ole 3 project at this stage, including ourselves as the initiators of the living lab initiative (i.e., the research group), those internal to the university and those in the external environment (private and public organizations). End users are key stakeholders in living labs, but without a common agreement with central stakeholders to commence with a living lab approach, as well as more solid funding, we found it immature at this point to start a wider involvement of ferry end users (i.e., the passengers).

\section{Step 2: Classification of stakeholders}

A classification scheme for our stakeholders and their attributes was made by combining the "rainbow diagram" (Chevalier \& Buckles, 2008) with the attitude-power-influence model proposed by Murray-Webster and Simon (2005). Table 1 presents these five attributes and their definition.

Our approach to the analysis was to do a subjective evaluation internally in the research group, based on data from interviews, meeting notes, email correspondence, websites, and personal subject-matter knowledge from the Ole 3 project. For our interviews, we developed an interview guide addressing aspects related to the five attributes (Table 1). Once data was gathered, we met to rate and classify stakeholders according to Table 1.

Our findings, reflecting our own interpretation of the stakeholders, were that they generally have a positive attitude (scoring in the range of 4 and 5), but that the influence, power, and degree to which the stakeholders are actually affected, was quite low (scoring in the range of 1 and 2).

\section{Step 3: Investigation of the relationships between stake- holders}

For this step, we applied a one-directional actor-linkage matrix (Biggs \& Matsaert, 1999). Reed and colleagues (2009) identify three dimensions of stakeholder relationships - conflict, complementary, and cooperation - and we chose to focus on the cooperative aspect of relationships, as we believed this was the most valuable at this stage. Then we undertook another subjective evaluation by scoring the strength of each relationship with values spanning from 1 (weak) to 3 (strong). A sample of the resulting matrix is presented in Table 2.

We found that there are significant variations in the strength of relationships between stakeholders. We also found differences in our subjective perceptions about both the nature of the relationships, as well as the relative strength of the stakeholders. Our stakeholder list contained both individuals and organizations, which added to this challenge. We recognized that relationships, even when our perspective is limited to collaborative aspects, 


\section{Exploring the Use of Stakeholder Analysis Methodology in the Establishment of a \\ Living Lab Marius Imset, Per Haavardtun, and Marius Stian Tannum}

Table 1. Stakeholder attributes and definitions on stakeholder properties

\begin{tabular}{|c|c|c|c|}
\hline Attribute & Definition (adapted by authors) & Scale & References \\
\hline Influence & $\begin{array}{l}\text { To what degree the stakeholder is able to informally } \\
\text { influence the living lab initiative }\end{array}$ & \multirow{2}{*}{ Least - Moderate - Most } & \multirow{2}{*}{ Chevalier \& Buckles, 2008} \\
\hline $\begin{array}{l}\text { Degree } \\
\text { affected }\end{array}$ & $\begin{array}{l}\text { To what degree the initiative/project, and the outcome } \\
\text { of it, will affect the situation for the stakeholder }\end{array}$ & & \\
\hline Power & $\begin{array}{l}\text { How much power/authority is held by stakeholders of } \\
\text { relevance to the initiative/project }\end{array}$ & Insignificant-Influential & \multirow{3}{*}{ Murray \& Webster, 2005} \\
\hline Attitude & $\begin{array}{l}\text { Stakeholders' current attitude towards the } \\
\text { initiative/project }\end{array}$ & Blocker - Backer & \\
\hline Interest & $\begin{array}{l}\text { How interested the stakeholder is in the } \\
\text { initiative/project }\end{array}$ & Passive-Active & \\
\hline
\end{tabular}

Table 2. Sample of results from relationship analysis

\begin{tabular}{|c|c|c|c|c|c|c|}
\hline Stakeholder & $\mathbf{0 1}$ & $\mathbf{0 2}$ & $\mathbf{0 3}$ & $\mathbf{0 4}$ & $\mathbf{0 5}$ & $\mathbf{0 6}$ \\
\hline 01 & & & & & & \\
\hline 02 & 3 & & & & & \\
\hline 03 & 3 & 3 & & & & \\
\hline 04 & 2 & 2 & 3 & & & \\
\hline 05 & 1 & 1 & 2 & 3 & & \\
\hline 06 & 1 & 3 & 3 & & 2 & \\
\hline
\end{tabular}

contain many sub-dimensions that needed clarification in order to secure reliability and validity of this type of analysis.

\section{Step 4: Reflect on the results and process}

As the final step, we reflected on the result and process, both individually and meetings. The results of these reflections are described in Table 3.

\section{The Second Iteration}

Based on our experiences from the first iteration, we made a number of changes in focus areas and research design for the second iteration. One of these changes was to shift from the meso (project) to the macro (organizational) level, in line with recommendations from Schuurman (2015). With respect to defining the organizational context, we chose to focus on our internal environment at the university. This is because of the central role of universities may play as generators and facilitators of quadruple-helix collaboration (Arnkil et al., 2010), and because we know from several years of experience that solid internal support is a key success factor in projects addressing multiple external stakeholders. During the first iteration, we also identified other projects going on among faculty, which addressed the same categories of external stakeholders. Typical for academic institutions with a high degree of individual autonomy (Winter, 2009), there was no common structure for how we should collaborate internally or with external parties in this new area of research. Thus, an internal analysis seemed necessary before moving on with external stakeholders.

Despite the common practice with third-party, subjective evaluations in stakeholder analysis, we find this approach to be doubtful in terms of both validity and reliability (Frankfort-Nachmias \& Nachmias, 2008). Thus, we wanted to measure the perceptions of stakeholders themselves, rather than using our own opinion. How a person perceives their fit with their job and organization was found by Cable and DeRue (2002) to be 


\section{Exploring the Use of Stakeholder Analysis Methodology in the Establishment of a Living Lab Marius Imset, Per Haavardtun, and Marius Stian Tannum}

Table 3. Lessons learned in the first iteration of stakeholder analysis (from Imset et al., 2018)

\begin{tabular}{|c|c|c|}
\hline & Lessons Learned & Comments \\
\hline 1 & $\begin{array}{l}\text { To list stakeholders is one thing, } \\
\text { following up is another. }\end{array}$ & $\begin{array}{l}\text { Secure time and resources, as well as good internal coordination. The creation of a } \\
\text { living lab may need to be established as a separate, formal project with funding. } \\
\text { Formalization may also increase understanding of the functions of a living lab and } \\
\text { make it clearer for internal participants to understand what their roles and tasks are. }\end{array}$ \\
\hline 2 & $\begin{array}{l}\text { Start with internal stakeholders in } \\
\text { own organization before moving } \\
\text { external. }\end{array}$ & $\begin{array}{l}\text { In a university environment such as ours, there is a plethora of related activities, } \\
\text { projects, and stakeholders that need to coordinate in order to provide a coherent } \\
\text { message to external stakeholders. }\end{array}$ \\
\hline 3 & $\begin{array}{l}\text { Plan and consider the first iteration } \\
\text { of stakeholder analysis as an } \\
\text { indication only. }\end{array}$ & $\begin{array}{l}\text { Stakeholder analysis is considered to be an iterative process (Reed, 2009), and this } \\
\text { aligns with our outcome and experiences. In terms of a living lab, we need to include } \\
\text { end users as well, but will await this involvement until the organizational aspect is } \\
\text { clearer. }\end{array}$ \\
\hline 4 & $\begin{array}{l}\text { Address individuals, not } \\
\text { organizations, in stakeholder } \\
\text { analysis. }\end{array}$ & $\begin{array}{l}\text { It is ultimately people who will contribute or resist, so we found that addressing } \\
\text { individuals was the most fruitful level of analysis. Mixing individuals and } \\
\text { organizations into the same analysis made the work difficult. }\end{array}$ \\
\hline 5 & $\begin{array}{l}\text { Stakeholder analysis requires a } \\
\text { clear, common understanding of } \\
\text { classification attributes. }\end{array}$ & $\begin{array}{l}\text { We developed and discussed the framework together in the research group, but } \\
\text { should have defined the meaning of the terms more thoroughly to secure a common } \\
\text { understanding. }\end{array}$ \\
\hline 6 & $\begin{array}{l}\text { A meso-level approach to the } \\
\text { establishment of a living lab is } \\
\text { challenging; a macro-level } \\
\text { approach may make it easier. }\end{array}$ & $\begin{array}{l}\text { It was difficult to isolate the project (meso) level from the organizational (macro) } \\
\text { level when analyzing issues related to the living lab (confirming Schuurman, 2015). } \\
\text { Thus, we believe it would have been better to start with a macro-level approach. }\end{array}$ \\
\hline
\end{tabular}

a better proximal determinant of attitudes and behaviours than the actual, or objective, fit. This supports the validity of data based on stakeholders' own perceptions of themselves and their relationships.

As our data collection tool, we chose to make an electronic survey. As constructs, we chose to continue with the stakeholder attributes according to Table 1, but our relationship construct applied in the third step of the first iteration needed revision.

Based on the challenges of separating the project from the organizational level in the first iteration, we also set forth to define a more focused, macro-level issue for the survey. This was of particular importance as we were to address the stakeholders directly. We also wanted to align our analysis with an ongoing strategic process on how to increase internal coordination and collaboration among faculty. Thus, we made the following introduction to the survey: "One goal in the faculty strategy is that we should improve internal communication, coordination, and collaboration. This stakeholder analysis is initiated to support this process: how we should organize our activities, with a particular focus on autonomous shipping (including ships, ports, logistics, and operations)." Note that in the maritime domain, shipping denotes waterborne transportation of both goods and people, including ferries.

The details of these adjustments in research design is elaborated below, under each step of the stakeholder analysis process.

\section{Step 1: Identification of stakeholders}

We used the same method as in the first iteration: defining a list based on our own perception. However, due to experiences from the first iteration, we now focused on people as individuals, and we ended up with a list of 13 stakeholders. Of the 13 surveys sent, 10 were returned. In order to secure anonymity, stakeholder names were replaced with capital letters. Acknowledging limitations in our own knowledge, and to obtain an increased understanding for future work, we also allowed respondents to identify new stakeholders they felt were 


\section{Exploring the Use of Stakeholder Analysis Methodology in the Establishment of a Living Lab Marius Imset, Per Haavardtun, and Marius Stian Tannum}

relevant. Due to time constraints, these additional stakeholders did not complete the survey but were considered in the relationship analysis.

\section{Step 2: Classification of (internal) stakeholders}

We used the same five stakeholder attributes as defined in Table 1, but added available time as a new factor. This is because time is a resource that affects most aspects of human enterprise, and therefore it is a central parameter in practical cost-benefit trade-offs (see Hollnagel, 2017, for an interesting elaboration on this). The survey contained six questions, one for each attribute, and respondents were asked to indicate their answers by use of a 5 point Likert-type scale (Table 4 ).

The respondents' answers were entered in the same type of spreadsheet as in the first iteration (see Imset et al., 2018, for details) and were coded with qualitative labels according to Table 5. Table 6 shows the results of the survey, with mean score and standard deviation for each of the concepts.

We found that the interest (mean score 4.4) and attitude (4.3) among the stakeholders is much higher than their perception of what they can do to help make the desired changes (influence is 2.8 and formal power is as low as 1.8). Time seems not to be the limiting aspect, as this is rated higher (3.3). These differences indicate that, although people feel affected and interested, there may be a lack of formal or informal ways to influence in decision-making processes related to the organizational layer.

\section{Step 3: Investigation of the relationships between stake-} holders

We continued to explore the collaborative aspect of relationships as we did in the first iteration. Human relationships may be analyzed using dozens of parameters,

Table 4. Stakeholder attributes and range of possible Likert-type responses to related survey questions on stakeholder properties

\begin{tabular}{llll} 
Attribute & Survey Question & Lowest Value (1) & Highest Value (5) \\
\hline Influence & $\begin{array}{l}\text { To what degree do you feel you are able to informally influence } \\
\text { this process? }\end{array}$ & No influence & Major influence \\
\hline $\begin{array}{l}\text { Degree } \\
\text { affected }\end{array}$ & $\begin{array}{l}\text { To what degree do you think this process, and the outcome of it, } \\
\text { will affect your work situation? }\end{array}$ & No change & Will totally change it \\
\hline Power & $\begin{array}{l}\text { Based on your formal position, how much power/authority do } \\
\text { you have in this process? }\end{array}$ & No control & Full control \\
\hline Attitude & What is your current attitude toward this process? & Totally negative & Totally positive \\
\hline Interest & How interested are you in this process? & No interest & Highly interested \\
\hline Time & $\begin{array}{l}\text { Do you have time available for improved communication and } \\
\text { collaboration? }\end{array}$ & No time & Time is no problem \\
\hline
\end{tabular}

Table 5. Classification labels for each attribute (adapted from Chevalier \& Buckles, 2008; Murray \& Webster 2005)

\begin{tabular}{|c|c|c|c|c|c|}
\hline Attribute / Score & $\mathbf{1}$ & $\mathbf{2}$ & $\mathbf{3}$ & $\mathbf{4}$ & $\mathbf{5}$ \\
\hline Influence & Least & Least & Moderate & Most & Most \\
\hline Degree affected & Least & Least & Moderate & Most & Most \\
\hline Power & Insignificant & Insignificant & Insignificant & Influential & Influential \\
\hline Attitude & Blocker & Blocker & Blocker & Backer & Backer \\
\hline Interest & Passive & Passive & Passive & Active & Active \\
\hline
\end{tabular}




\section{Exploring the Use of Stakeholder Analysis Methodology in the Establishment of a Living Lab Marius Imset, Per Haavardtun, and Marius Stian Tannum}

Table 6. Table with properties of each stakeholder

\begin{tabular}{|c|c|c|c|c|c|c|c|c|c|c|c|}
\hline \multirow[b]{2}{*}{ Stakeholder } & \multirow[t]{2}{*}{ Time } & \multicolumn{2}{|c|}{ Rainbow Diagram } & \multicolumn{3}{|c|}{ Three-Dimensional Grouping } & \multirow{2}{*}{\multicolumn{3}{|c|}{ Label }} & \multirow{2}{*}{\multicolumn{2}{|c|}{ Label }} \\
\hline & & \multirow[t]{2}{*}{ Influence } & \multirow[t]{2}{*}{$\begin{array}{c}\text { Degree } \\
\text { Affected }\end{array}$} & \multirow[t]{2}{*}{ Power } & \multirow[t]{2}{*}{ Attitude } & \multirow[t]{2}{*}{ Interest } & & & & & \\
\hline$A$ & & & & & & & & & & & \\
\hline B & 3 & 3 & 3 & 1 & 5 & 5 & Insignificant & Active & Backer & Moderate Influence & Moderate Affected \\
\hline $\mathrm{C}$ & 3 & 1 & 1 & 1 & 3 & 2 & Insignificant & Passive & Blocker & Least Influence & Least Affected \\
\hline $\mathrm{D}$ & 3 & 3 & 3 & 1 & 5 & 5 & Insignificant & Active & Backer & Moderate Influence & Moderate Affected \\
\hline$E$ & 4 & 4 & 3 & 3 & 4 & 4 & Insignificant & Active & Backer & Most Influence & Moderate Affected \\
\hline $\mathrm{F}$ & & & & & & & & & & & \\
\hline G & & & & & & & & & & & \\
\hline $\mathrm{H}$ & 4 & 2 & 4 & 1 & 3 & 5 & Insignificant & Active & Blocker & Least Influence & Most Affected \\
\hline I & 2 & 3 & 4 & 3 & 5 & 5 & Insignificant & Active & Backer & Moderate Influence & Most Affected \\
\hline $\mathrm{J}$ & 3 & 3 & 3 & 2 & 5 & 4 & Insignificant & Active & Backer & Moderate Influence & Moderate Affected \\
\hline $\mathrm{K}$ & 3 & 3 & 3 & 4 & 3 & 4 & Influential & Active & Blocker & Moderate Influence & Moderate Affected \\
\hline $\mathrm{L}$ & 4 & 3 & 4 & 1 & 5 & 5 & Insignificant & Active & Backer & Moderate Influence & Most Affected \\
\hline$M$ & 4 & 3 & 4 & 1 & 5 & 5 & Insignificant & Active & Backer & Moderate Influence & Most Affected \\
\hline Mean & 3.3 & 2.8 & 3.2 & 1.8 & 4.3 & 4.4 & & & & & \\
\hline SD & 0.67 & 0.79 & 0.92 & 1.14 & 0.95 & 0.97 & & & & & \\
\hline
\end{tabular}

but including all of these in a survey would make the survey too onerous for the respondents. As we prioritized to make the survey accessible and quick to complete, we chose to explore two central properties. The first is intensity, defined as "the strength of the relation between individuals", and the second reciprocity, defined as "the degree to which a relation is commonly perceived and agreed on by all parties to the relation, i.e. the degree of symmetry" (Tichy et al., 1979). By means of our electronic survey, we measured the intensity of the relationship by questions addressing three sub-properties in line with Dagger and co-authors (2009): extent of collaboration, contact frequency, and motivation for increased collaboration in the fu- ture. The three questions are shown in Table 7 along with the Likert-type scale. Frequency intervals were also added to increase reliability.

In order to condense our analysis and data, we calculated the mean value of the two first questions in Table 7 as one value for the degree of current collaboration, whereas the latter questions represent the motivation for more future collaboration. The reciprocity (symmetry) of the relationship has been calculated as the absolute value of the differences in how two stakeholders rated their common relationship. This means that the lower the calculated value, the more symmetric are the relationships.

Table 7. Survey questions for measuring the intensity of each relationship

\begin{tabular}{|c|c|c|c|c|c|}
\hline Question & $\begin{array}{c}\text { Low } \\
1\end{array}$ & 2 & 3 & 4 & $\begin{array}{c}\text { High } \\
5\end{array}$ \\
\hline $\begin{array}{l}\text { To what extent do you collaborate today with } \\
\text { him/her on ideation, application development, or } \\
\text { project work related to autonomous shipping? }\end{array}$ & $\begin{array}{l}\text { Less than } 5 \\
\text { hours a } \\
\text { year }\end{array}$ & $\begin{array}{c}\text { 5-50 hours } \\
\text { a year }\end{array}$ & $\begin{array}{l}50-150 \\
\text { hours a } \\
\text { year }\end{array}$ & $\begin{array}{l}150-300 \\
\text { hours a } \\
\text { year }\end{array}$ & $\begin{array}{c}300+\text { hours } \\
\text { a year }\end{array}$ \\
\hline $\begin{array}{l}\text { How often do you have contact with him/her in } \\
\text { order to discuss future collaboration and ideas in } \\
\text { autonomous shipping? }\end{array}$ & $\begin{array}{c}\text { Less than } \\
\text { once a year }\end{array}$ & $\begin{array}{c}1-5 \text { times a } \\
\text { year }\end{array}$ & $\begin{array}{c}\text { 5-15 times } \\
\text { a year }\end{array}$ & $\begin{array}{c}\text { 15-30 times } \\
\text { a year }\end{array}$ & $\begin{array}{c}30+\text { times a } \\
\text { year }\end{array}$ \\
\hline
\end{tabular}

Based on your current working situation and knowledge, to what degree are you interested in more collaboration with him/her on autonomous shipping?

$\begin{array}{ccccc}\begin{array}{c}\text { Not } \\ \text { interested }\end{array} & \ldots & \ldots & \ldots & \text { Highly } \\ \text { interested }\end{array}$




\section{Exploring the Use of Stakeholder Analysis Methodology in the Establishment of a Living Lab Marius Imset, Per Haavardtun, and Marius Stian Tannum}

The relational data are presented as social network diagrams (Scott, 2017) along with tables presenting more information about the nature of the relation (ties), with values for tie strength and reciprocity. Also, mean values and standard deviation (SD) were calculated. First, we present our findings for the current degree of collaboration, then for the motivation for increased collaboration in the future.

\section{Strength of current collaboration}

We received data on a total of 82 ties, of which 44 were mutual (Figure 2). The difference in these numbers are due to the fact that three respondents did not return the survey and because some respondents added new stakeholders to the list. Details of these ties are provided in Table 8.

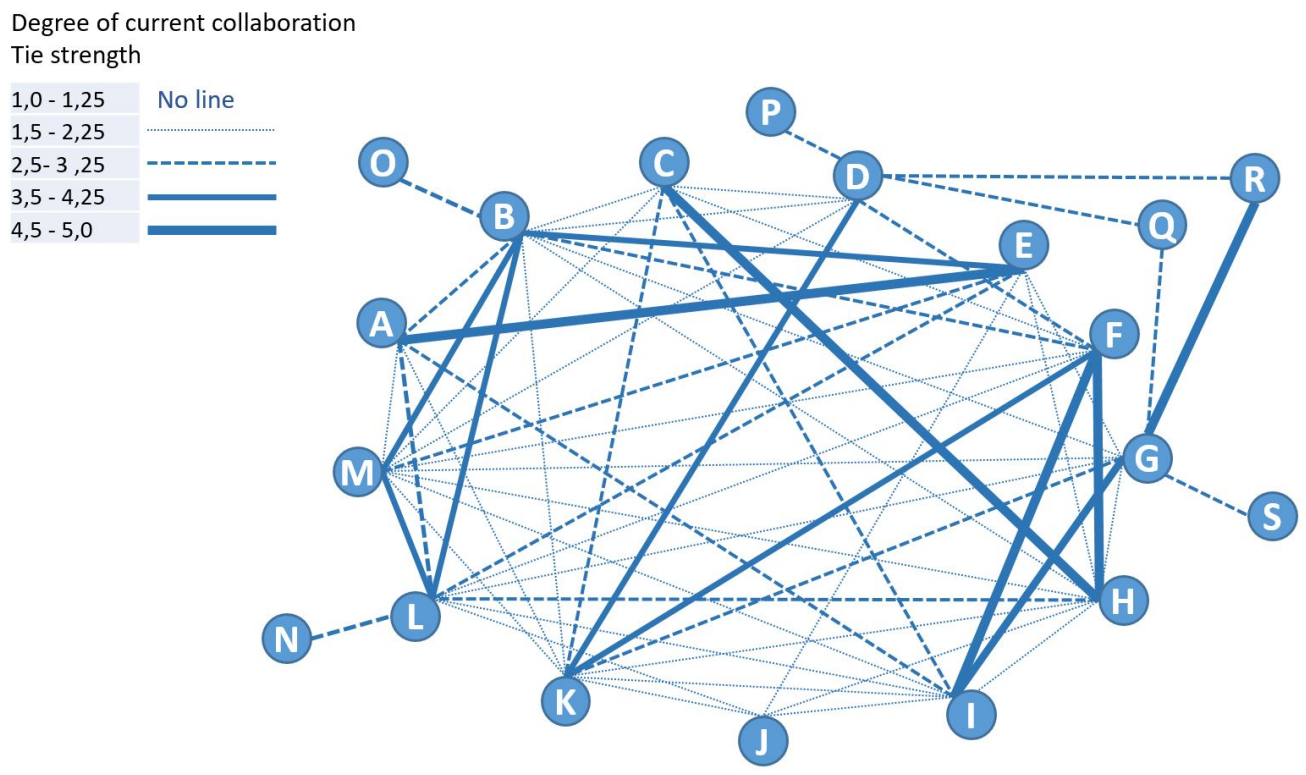

Figure 2. Social network diagram illustrating the current degree of collaboration (time spent together and contact frequency taken into account) between the stakeholders. Tie strength ranges from 1 (low) to 5 (high). The initial 13 stakeholders (A to $\mathrm{M}$ ) are placed in a central group; stakeholders added during the survey ( $\mathrm{N}$ to $\mathrm{S}$ ) are placed outside the group.

Table 8. Overview of variation in tie strength and reciprocity in current collaboration. Mean value of all ties = 2.08; standard deviation of all ties $=1.09$.

\begin{tabular}{|c|c|}
\hline \multicolumn{2}{|c|}{ Tie Strength } \\
\hline Value & Count \\
\hline $1-1.25$ & 22 \\
\hline $1.5-2.25$ & 30 \\
\hline $2.5-3.25$ & 19 \\
\hline $3.5-4.25$ & 5 \\
\hline $4.5-5$ & 6 \\
\hline Sum ties & $\mathbf{8 2}$ \\
\hline
\end{tabular}

\begin{tabular}{|c|c|c|}
\hline \multicolumn{2}{|c|}{ Mutual Ties/Relational Symmetry } \\
\hline Value & Count & Reciprocity \\
\hline 0 & 10 & High \\
\hline 0.5 & 17 & $\cdot$ \\
\hline 1 & 9 & $\cdot$ \\
\hline 1.5 & 4 & $\cdot$ \\
\hline 2 & 4 & Low \\
\hline Sum mutual ties & $\mathbf{4 4}$ & \\
\hline
\end{tabular}




\section{Exploring the Use of Stakeholder Analysis Methodology in the Establishment of a Living Lab Marius Imset, Per Haavardtun, and Marius Stian Tannum}

We see that the existing network has some degree of collaboration, but most ties (42) are at 2.25 or lower (i.e., towards the lower end of the scale). The overall mean value of 2.08 is influenced by a few strong ties (11 are rated at 3.5 or higher). This is reflected in the standard deviation of 1.09 . It seems as though relationships are quite symmetrical, as 27 of the total of 44 mutual ties has only 0.5 or less difference in score. However, there are also some examples of big differences, there are 8 ties with 1.5 or 2 .

Motivation for increased collaboration in the future For future collaboration, the mean value is 3.65 , which is towards the upper part of the scale. Thirty of the 44 mutual ties have values of 1 or less, indicating a high degree of symmetry. But, there are also 4 relationships that score 3 , meaning that one party is highly motivated for more collaboration, while the other is not. Lack of symmetry does thus not seem to be a big challenge, as the majority of relationships are based on mutual expectations and motivation. A high degree of symmetry was also confirmed by computing the averages of the overall received and delivered score values among the respondents, where we found only a slight difference (0.2) related to one issue (contact frequency). Details of these ties are provided in Figure 3 and Table 9.

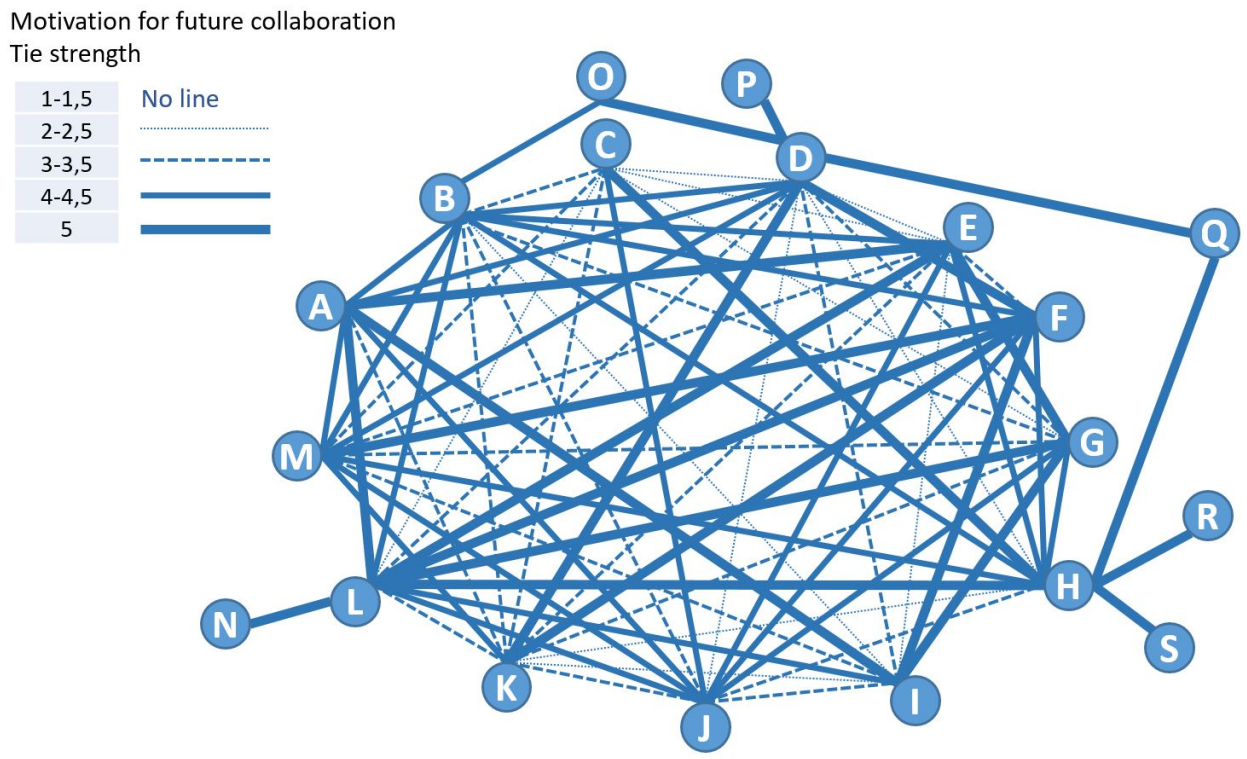

Figure 3. Social network diagram illustrating the degree of motivation for increased collaboration between the stakeholders. Tie strength ranges from 1 (low) to 5 (high). The initial 13 stakeholders (A to M) are placed in a central group; stakeholders added during the survey ( $\mathrm{N}$ to $\mathrm{S}$ ) are placed outside the group.

Table 9. Overview of variation in tie strength and reciprocity for increased collaboration. Mean value of all ties = 3.65; standard deviation of all ties $=1.26$.

\begin{tabular}{|c|c|}
\hline \multicolumn{2}{|c|}{ Tie Strength } \\
\hline Value & Count \\
\hline $1-1.5$ & 4 \\
\hline $2-2.5$ & 12 \\
\hline $3-3.5$ & 20 \\
\hline $4-4.5$ & 24 \\
\hline 5 & 22 \\
\hline Sum ties & $\mathbf{8 2}$ \\
\hline
\end{tabular}

\begin{tabular}{|c|c|c|}
\hline \multicolumn{2}{|c|}{ Mutual Ties/Relational Symmetry } \\
\hline Value & Count & Reciprocity \\
\hline 0 & 12 & High \\
\hline 1 & 18 & $\cdot$ \\
\hline 2 & 10 & $\cdot$ \\
\hline 3 & 4 & $\cdot$ \\
\hline 4 & 0 & Low \\
\hline Sum mutual ties & $\mathbf{4 4}$ & \\
\hline
\end{tabular}




\section{Exploring the Use of Stakeholder Analysis Methodology in the Establishment of a Living Lab Marius Imset, Per Haavardtun, and Marius Stian Tannum}

We also analyzed how available time may affect the degree of motivation, and we found a moderate to high correlation (Pearson $=0.53$ ). This implies that people with less time are also less interested in increased collaboration, confirming that available time is an important attribute in stakeholder analysis.

\section{Step 4: Reflect on the results and process}

To us, the most interesting finding is the large difference between the current and desired degree of collaboration. Stakeholders feel that the degree of current collaboration is low, and that they would like to increase it in the future. This is promising for the establishment of a living lab. They also feel that there is time for more collaboration, but that their possibilities to influence (formal and informal power) how we work and collaborate is low. Given that the university is to become a central stakeholder in the living lab establishment, this seems to be a main barrier that needs to be further explored. Principally there may also be other leading organizations besides the university, or the living lab may also be based on other network models (Barabasi, 2002) that are not centralized. However, to our knowledge, few other relevant internal and external stakeholders are aware of the concept of living labs, and in our region, the university would likely be expected to have some sort of hub function.

We were also surprised to see that the degree of symmetry, or reciprocity, in the motivation for more collaboration is so high, when the degree of current collaboration is low. We interpret this as an indication of general positive attitudes toward getting to know one another better. Promoting the living lab concept may help to facilitate a better understanding of how to collaborate. We provide an overview of our lessons learned from the process in Table 10.

Table 10. Lessons learned from the stakeholder analysis method applied in the second iteration

\begin{tabular}{lll}
\hline Issue & Lessons Learned \\
\hline $1 \quad$ Relevance of findings & $\begin{array}{l}\text { The method revealed findings that were highly relevant and interesting to our action research } \\
\text { context. Asking respondents themselves increases data validity. }\end{array}$ \\
\hline $2 \quad \begin{array}{l}\text { The process created } \\
\text { engagement, curiosity, } \\
\text { and awareness in the } \\
\text { organization }\end{array}$ & $\begin{array}{l}\text { We were approached by both colleagues and managers who expressed their interest, and we } \\
\text { expect that the results will be received with great interest by the participating stakeholders. }\end{array}$ \\
\hline $\begin{array}{l}\text { Unit of analysis in } \\
\text { stakeholder analysis }\end{array}$ & $\begin{array}{l}\text { Addressing stakeholders as individuals made it easier to work systematically (compared to the } \\
\text { first iteration), and we also found a lot of variation within the organization. }\end{array}$ \\
\hline $\begin{array}{l}\text { Data privacy } \\
\text { Some respondents were very concerned about data privacy. Although we formulated our }\end{array}$ \\
$\begin{array}{ll}\text { questions to address strictly professional aspects of the relationship, some of the respondents } \\
\text { felt that data concerning relationships between colleagues was principally sensitive. }\end{array}$
\end{tabular}

$5 \quad$ Anonymization

6 Resource need for stakeholder analysis

$7 \quad$ Limitations on the number of stakeholders

$8 \quad$ Keep it focused

Due to ethical principles in science (anonymity), we chose to anonymize respondents. This may reduce the usefulness of the analysis in plenary discussions in the faculty.

Preparations, data collection, and analysis using this method is time consuming compared to a third-party assessment (where data is based on assumptions about stakeholder properties and relationships)

Adding a larger number of stakeholder into this type of survey, that also explores relationships, will make it hard to use in practice for the respondents. Based on feedback from our respondents we estimate that an upper limit of approximately 20 stakeholders is appropriate.

Based on the feedback we received, we succeeded in providing a clear focus for this iteration.

9 Selection of respondents

As for the first iteration, we decided on which stakeholders to include in the analysis. In the second iteration, we allowed the respondents to add new relevant stakeholders into the survey data. We found this to be a valuable addition for follow up work. 


\section{Exploring the Use of Stakeholder Analysis Methodology in the Establishment of a Living Lab Marius Imset, Per Haavardtun, and Marius Stian Tannum}

\section{Discussion}

Although the first iteration followed the basic principles of stakeholder analysis, the subjective approach and an ill-defined relationship construct reduces the scientific validity and reliability. Based on our limited literature review, this seems to be a common challenge in much of the available methodology, not only for living labs, but also for the wider field of innovation.

The second iteration used methods that are more reliable and valid, and with a scope and focus that we found more useful at our current stage. The actual involvement of the stakeholders also sparked engagement. However, there are practical drawbacks with these changes, which is that the second approach required significantly more resources and expertise. Still, there is a long way to go from our simple questionnaire to a scientifically solid scale measure (e.g., exploratory factor analysis: Costello \& Osborne, 2005), but such development is outside the scope of this work.

Based on our experience with project development, we find it unlikely that practitioners are willing to undertake a very extensive analysis for exploring their stakeholders (potentially with the exception of systematic user studies addressing particular issues related to the product or service being developed). Thus, a simpler approach seems needed - one that still ensures a satisfactory level of reliability and validity. The similarities and differences of our two iterations is summarized in Table 11.

\section{Conclusion}

In accordance with methodologies for stakeholder analysis and action research, we conducted a stakeholder analysis in two iterations. We applied two different approaches in order to explore which is better in terms of costs and benefits for living labs practice. The action research has been conducted in the context of the initial phase of a living lab for increased autonomy in the maritime shipping industry. Due to the early stage of this project, we have chosen to focus on the internal organizational layer, before reaching out to external stakeholders such as industry and end users. Our research indicates that a thorough, scientifically solid stakeholder analysis provides higher value, but may be too costly or complex compared to simpler methods. We propose that our approach applied in the second iteration provide a good cost-benefit balance suited for living lab development and related open innovation initiatives.

\section{Acknowledgements}

This article was developed from a paper presented at the ISPIM Innovation Conference in Stockholm, Sweden, June 17-20, 2018. ISPIM (ispim-innovation.com) the International Society for Professional Innovation Management - is a network of researchers, industrialists, consultants, and public bodies who share an interest in innovation management.

\section{About the Authors}

Marius Imset is an Associate Professor in Product Design at the University of South-Eastern Norway. He has more than twenty years of experience in management of and participation in industrial and academic $R \& D$ projects. His expertise is in product design, innovation management, and organizational change. In the maritime industry, he conducts research in the field of human factors with a special focus on cognitive situation assessment and decision making.

Per Haavardtun is an Assistant Professor in the Maritime Institute of the University of South-Eastern Norway. He has expertise in maritime operations with respect to deck officers in accordance with the regulations of the International Maritime Organization (IMO). He also has expertise in cost accounting, business development, innovation, and entrepreneurship. He currently studies human factors in automated and autonomous maritime vessels.

Marius Tannum is an Assistant Professor in the field of Maritime Electronics and Automation at the University of South-Eastern Norway. He received his Master's degree in Electrical Power Systems from the Norwegian University of Science and Technology with a focus on power electronics and control. Marius has more than 12 years of industry work experience with $R \& D$ related to electrical power converters and as the Head of R\&D for a start-up company in the field of automation. His main interest is now maritime power and autonomous systems. 


\section{Exploring the Use of Stakeholder Analysis Methodology in the Establishment of a \\ Living Lab Marius Imset, Per Haavardtun, and Marius Stian Tannum}

Table 11. Overview of differences in research design in the first and second iteration, including our evaluation of strengths and limitations of the two approaches

\begin{tabular}{lll}
\hline Aspect & First Iteration & Second Iteration \\
\hline Living lab level addressed & Meso & Macro \\
\hline Scope & Quadruple helix & Intra-organizational \\
\hline Data collection method & $\begin{array}{l}\text { Evaluating stakeholders (external } \\
\text { assessment by the researchers) }\end{array}$ & $\begin{array}{l}\text { Asking stakeholders using a survey (self- } \\
\text { assessment) }\end{array}$ \\
\hline Stakeholder types & $\begin{array}{l}\text { Mix of organizations, groups, and } \\
\text { individuals }\end{array}$ & $\begin{array}{l}\text { Individuals only, but at different levels } \\
\text { in the organization }\end{array}$ \\
\hline
\end{tabular}

Step 1: Identify stakeholders

Defined by research group/authors.

In the second iteration, we allowed stakeholders to suggest other stakeholders.

Step 2: Classify stakeholders research design

Step 2: Stakeholder attributes

Step 3: Investigate the relationships between stakeholders
Researchers' perception of stakeholders Stakeholders' own perception

5 stakeholder attributes (Table 1)

The same 5 attributes, plus time

Researchers' perceptions of stakeholders

One factor, uni-directional

Stakeholders' own perceptions; data collection by a survey

Three dimensions

Bi-directional

Collaboration; ill-defined

Research group only; during and after the process, individual, and in plenary properties spontaneous reflections on
Collaboration; better defined, with sub-

Similar as in the first iteration and also methodology from stakeholders participating in the analysis

\begin{tabular}{lll} 
Reliability and validity & Low & Mediur \\
\hline $\begin{array}{l}\text { Cost (sum of time spent from all } \\
\text { parties) }\end{array}$ & Very low & High
\end{tabular}




\section{Exploring the Use of Stakeholder Analysis Methodology in the Establishment of a \\ Living Lab Marius Imset, Per Haavardtun, and Marius Stian Tannum}

\section{References}

Allen, S., Bailetti, T., \& Tanev, S. 2009. Components of Co-creation. Open Source Business Resource, November 2009: 11-18.

https://timreview.ca/article/301

Arnkil, R., Järvensivu, A., Koski, P., \& Piirainen, T. 2010. Exploring Quadruple Helix Outlining User-Oriented Innovation Models. Working paper. Tampere, Finland: University of Tampere.

Barabasi, A. L. 2002. Linked: The New Science of Networks. Cambridge: Perseus Publishing.

Biggs, S., \& Matsaert, H. 1999. An Actor-Oriented Approach for Strengthening Research and Development Capabilities in Natural Resource Systems. Public Administration and Development: The International Journal of Management Research and Practice, 19(3): 231-262.

Cable, D. M., \& DeRue, D. S. 2002. The Convergent and Discriminant Validity of Subjective Fit Perceptions. Journal of Applied Psychology, 87(5): 875-884. http://dx.doi.org/10.1037/0021-9010.87.5.875

Chesbrough, H. W. 2006. Open Innovation: The New Imperative for Creating and Profiting from Technology. Boston, MA: Harvard Business Press.

Chevalier, J. M., \& Buckles, D. J. 2008. SAS2: A Guide to Collaborative Inquiry and Social Engagement. Ottawa: International Development Research Centre.

Costa, C., \& Cunha, P. 2010. Who Are the Players? Finding and Characterizing Stakeholders in Social Networks. In Proceedings of the 43rd Hawaii International Conference on System Sciences, January 5-8, 2010. Honolulu, HI.

http://dx.doi.org/10.1109/HICSS.2010.443

Costello, A. B., \& Osborne, J. W. 2005. Best Practices in Exploratory Factor Analysis: Four Recommendations for Getting the Most from Your Analysis. Practical Assessment, Research \& Evaluation, 10(7): $1-9$.

Dagger, T. S., Danaher, P. J., \& Gibbs, B. J. 2009. How Often Versus How Long: The Interplay of Contact Frequency and Relationship Duration in Customer-Reported Service Relationship Strength. Journal of Service Research, 11(4): 371-388. https://doi.org/10.1177/1094670508331251

De Oliveira Monteiro, S. P., \& Carayannis, E. G. (Eds.). 2017. The Quadruple Innovation Helix Nexus: A Smart Growth Model, Quantitative Empirical Validation and Operationalization for OECD Countries. New York: Palgrave Macmillan. https://doi.org/10.1057/978-1-137-55577-9

Diefenbach, T., \& Sillince, J. A. A. 2011. Formal and Informal Hierarchy in Different Types of Organization. Organization Studies, 32(11): 1515-1537.

https://doi.org/10.1177/0170840611421254

Drèze, J., \& Stern, N. 1987. The Theory of Cost-Benefit Analysis. In A. J. Auerbach \& M. Feldstein (Eds.), Handbook of Public Economics, Vol. 2: 909-989. Oxford: Elsevier.

Frankfort-Nachmias, C., \& Nachmias, D. 2008. Research Methods in the Social Sciences (7th edition). New York, NY: Worth Publishers.

Freeman, R. E. 1984. Strategic Management: A Stakeholder Approach. Boston, MA: Pitman.
Glenn, S. M., Dickey, T. D., Parker, B., \& Boicourt, W. 2000. LongTerm Real-Time Coastal Ocean Observation Networks. Oceanography, 13(1): 24-34.

https://doi.org/10.5670/oceanog.2000.50

Greenwood, D. J., \& Levin, M. 2006. Introduction to Action Research: Social Research for Social Change. Thousand Oaks, CA: SAGE Publications.

Heikkinen, M. T., Mainela, T., Still, J., \& Tähtinen, J. 2007. Roles for Managing in Mobile Service Development Nets. Industrial Marketing Management, 36(7): 909-925.

https://doi.org/10.1016/j.indmarman.2007.05.014

Hollnagel, E. 2017. The ETTO Principle: Efficiency-Thoroughness Trade-Off: Why Things That Go Right Sometimes Go Wrong. Boca Raton, FL: CRC Press.

Hughes, T. 2014. Co-Creation: Moving Towards a Framework for Creating Innovation in the Triple Helix. Prometheus, 32(4): 337-350.

http://dx.doi.org/10.1080/08109028.2014.971613

Imset, M., Haavardtun, P., Knutson, S., Tannum, M. S., \& Aamaas, P. 2018. Initiating a Living Lab for Autonomous Ferries Using Stakeholder Analysis. Paper presented at the 2018 ISPIM Innovation Conference in Stockholm, Sweden, June 17-20, 2018.

Jonker, J., \& Foster, D. 2002. Stakeholder Excellence? Framing the Evolution and Complexity of a Stakeholder Perspective of the Firm. Corporate Social Responsibility and Environmental Management, 9(4): 187-195.

https://doi.org/10.1002/csr.23

Keyson, D. V., Guerra-Santin, O., \& Lockton, D. 2017. Living Labs: Design and Assessment of Sustainable Living. Delft, The Netherlands: Springer.

http://dx.doi.org/10.1007/978-3-319-33527-8

Kim, J., \& Wilemon, D. 2002. Focusing the Fuzzy Front-End in New Product Development. R\&D Management, 32(4): 269-279. https://doi.org/10.1111/1467-9310.00259

Kolb, D. A. 2014. Experiential Learning: Experience as the Source of Learning and Development. Upper Saddle River, NJ: FT Press.

Kivits, R. A. 2011. Three Component Stakeholder Analysis. International Journal of Multiple Research Approaches, 5(3): 318-333.

http://dx.doi.org/10.5172/mra.2011.5.3.318

Kyvik, S., \& Reymert, I. 2017. Research Collaboration in Groups and Networks: Differences across Academic Fields. Scientometrics, 113(2): 951-967.

http://dx.doi.org/10.1007/s11192-017-2497-5

Logghe, S., \& Schuurman, D. 2017. Action Research as a Framework to Evaluate the Operations of a Living Lab. Technology Innovation Management Review, 7(2): 35-41.

http://dx.doi.org/10.22215/timreview/1056

Miron, D., \& Gherasim, I. 2018. Linking the Triple Helix (UniversityIndustry-Government) to the Quadruple Helix of UniversityIndustry-Government - Civil Society in the Field of International Business and Economics. Proceedings of the International Conference on Business Excellence, 12(1): 612-625. https://doi.org/10.2478/picbe-2018-0055

Murray-Webster, R., \& Simon, P. 2006. Making Sense of Stakeholder Mapping. PM World Today, 8(11): 1-5. 


\section{Exploring the Use of Stakeholder Analysis Methodology in the Establishment of a \\ Living Lab Marius Imset, Per Haavardtun, and Marius Stian Tannum}

Nyström, A.-G., Leminen, S., Westerlund, M., \& Kortelainen, M. 2014. Actor Roles and Role Patterns Influencing Innovation in Living Labs. Industrial Marketing Management, 43(3): 483-495.

http://dx.doi.org/10.1016/j.indmarman.2013.12.016

Øvergård, K. I., Tannum, M. S., Haavardtun, P., \& Syversen, J. K. B. 2017. Chase, No Straighter: COLREG Compliant Anti-Collision Manoeuvers for Crossing Situations. Robotic Sailing 2017: 81-91. http://dx.doi.org/10.1007/978-3-319-72739-4_7

Reed, M. S., Graves, A., Dandy, N., Posthumus, H., Hubacek, K., Morris, J., Prell, C., Quinn C. H., \& Stringer, L. C. 2009. Who's In and Why? A Typology of Stakeholders Analysis Methods for Natural Resource Management. Journal of Environmental Management, 90(5): 1933-1949.

https://doi.org/10.1016/j.jenvman.2009.01.001

Robles, A. G., Hirvikoski, T., Schuurman, D., \& Stokes, L. 2015. Introducing ENoLL and Its Living Lab Community. Brussels: European Network of Living Labs (ENoLL).

Rogers, J. D. 2000. Theoretical Consideration of Collaboration in Scientific Research. In S. Hauger \& C. McEnaney (Eds), Strategies for Competitiveness in Academic Research: 151-178. Washington DC: American Association for the Advancement of Science.

Savage, G. T., Nix, T. W., Whitehead, C. J., \& Blair, J. D. 1991. Strategies for Assessing and Managing Organizational Stakeholders. The Executive, 5(2): 61-75.

Scott, J. 2017. Social Network Analysis. Thousand Oaks, CA: SAGE Publications.

Schuurman, D. 2015. Bridging the Gap between Open and User Innovation? Exploring the Value of Living Labs as a Means to Structure User Contribution and Manage Distributed Innovation. Dissertation. Ghent, Belgium: Ghent University.

Schuurman, D., \& De Marez, L. 2012. Structuring User Involvement in Panel-Based Living Labs. Technology Innovation Management Review, 2(9): 31-38. http://doi.org/10.22215/timreview/606
Skredderberget, A. 2018. The First Ever Zero Emission, Autonomous Ship. Yara.com, March 14, 2018. Accessed November 1, 2018: http://yara.com/media/stories/yara_birkeland_vessel_zero_emissi on.aspx

Ståhlbröst, A. 2008. Forming Future IT: The Living Lab Way of User Involvement. Dissertation. Luleå, Sweden: Luleå University of Technology.

Ståhlbröst, A., \& Holst, M. 2012. The Living Labs Methodology Handbook. Luleå, Sweden: Luleå University of Technology.

Tanev, S., Knudsen, M. P., Bisgaard, T., \& Thomsen, M. S. 2011. Innovation Policy Development and the Emergence of New Innovation Paradigms. Technology Innovation Management Review, 1(2): 14-19.

http://doi.org/10.22215/timreview/496

Tichy, N. M., Tushman, M. L., \& Fombrun, C. 1979. Social Network Analysis for Organizations. Academy of Management Review, 4(4): 507-519.

https://doi.org/10.5465/amr.1979.4498309

Winter, R. 2009. Academic Manager or Managed Academic? Academic Identity Schisms in Higher Education. Journal of Higher Education Policy and Management, 31(2): 121-131. https://doi.org/10.1080/13600800902825835

Citation: Imset, M., Haavardtun, P., Tannum, M. S. 2018. Exploring the Use of Stakeholder Analysis Methodology

(cc) BY in the Establishment of a Living Lab. Technology Innovation Management Review, 8(12): 26-39. http://doi.org/10.22215/timreview/1203

Keywords: living labs, stakeholder analysis, autonomous vessels, maritime, open innovation, action research, quadruple helix, management 


\section{Academic Affiliations and Funding Acknowledgements}

Canadà
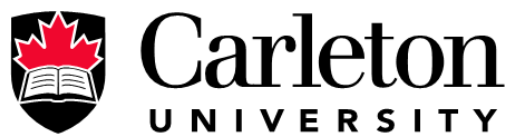

U N I V E R S I T Y

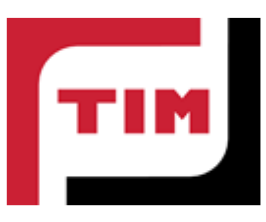

The Federal Economic Development Agency for Southern Ontario (FedDev Ontario; feddevontario.gc.ca) is part of the Innovation, Science and Economic Development portfolio and one of six regional development agencies, each of which helps to address key economic challenges by providing regionallytailored programs, services, knowledge and expertise.

- The TIM Review receives partial funding from FedDev Ontario's Investing in Regional Diversification initiative.

Technology Innovation Management (TIM; timprogram.ca) is an international master's level program at Carleton University in Ottawa, Canada. It leads to a Master of Applied Science (M.A.Sc.) degree, a Master of Engineering (M.Eng.) degree, or a Master of Entrepreneurship (M.Ent.) degree. The objective of this program is to train aspiring entrepreneurs on creating wealth at the early stages of company or opportunity lifecycles.

- The TIM Review is published in association with and receives partial funding from the TIM program. 